\title{
Influences on tourism destination image beyond marketing: people, power, place
}

\author{
Kevin Tavares \\ This study was conducted under the supervision of Professor Statia Elliot, \\ Hospitality and Tourism Management, College of Management Economics \\ University of Guelph
}

\begin{abstract}
Tourism destination image, henceforth referred to as TDI, is a concept that many researchers have studied in efforts to understand its creation, implementation, promotion and benefit. Academic researchers have forayed into these aspects of TDI in a multitude of ways, in hopes of understanding how this concept is relevant to the industry. The majority of academic research conducted in TDI has been studied from a marketing perspective, with limited consideration of additional influences on image. This paper aims to analyze the influence that non- marketing, social factors such as heritage, culture, place identity, stakeholder involvement, politics and gender play in relation to destination image. The result is a holistic model of TDI as a broad social science construct.
\end{abstract}

$\mathrm{M}$ uch has been written about destination image in terms of its relation to the supply and demand sides of marketing. Tourism destination image can therefore be defined as [1] "the sum of beliefs, ideas, and impressions that a person has of a destination." TDI has been studied in a multitude of ways including its influence on the decision making of potential tourists [2], as a measurement of public perception of place [3], and as a way to package aesthetically pleasing aspects of a place [4]. A particular area of focus is the impact that destination image can have on most every stakeholder from the local residents to the potential tourist [5]. Research has also been clear in stating that destination images are never static and can range on a continuum from positive to negative with constant change. In addition, images can have varying levels of influence on different stakeholders and can never be completely positive. There are always partial images of negative associations with every destination image regardless of the efforts invested in its change [6].

Current studies of tourism destination image often use words such as "integrated" or "amalgamated" approaches to studying destination image. This suggests that all facets of destination image have been scrutinized, in order to analyze their potential influence. However, a review of the literature seems to point more towards a fragmented approach to the study of TDI [7]. With an emphasis on the role of TDI in relation to marketing, numerous authors have touched on non-marketing influences on place identity. These studies all tackle separate segments of TDI, yet an overarching comprehensive gathering of these aspects is lacking. This paper will consider a broad range of TDI influences from the social science domain leading to the development of a more holistic model of tourism destination image.

\section{LITERATURE REVIEW}

Social science is the study of human society and of individual relationships in and to society [8]. Tourism has been examined from numerous perspectives in an attempt to gauge the potential benefits versus consequences. Social sciences relate to destinations in that they are unique, original aspects of human society that provide value and are differentiated from other destinations [9]. Social science influences relevant to TDI include heritage, culture, place identity, stakeholder involvement, politics and gender.

\section{Influence of heritage}

Heritage is a discipline of the social sciences that has much to do with the development of image. It deals with the application and development of past occurrences and history not only as symbols of place, but also as modern day elements of tourism [10]. Heritage has a significant impact on a destination's image because it is highly integrated within other aspects of the tourism industry [11]. A destination's heritage has been proven to have considerable effect on one's perceptions and evaluations, and thus on one's cognitive and affective image of place [10]. Heritage and history conjure up feelings and emotions that directly influence place identity by associating these feelings and emotions to a unique mental image [12]. It has also been attributed to the improvement and restoration of place image [11] and to the provision of developing place identity [13]. It 
can be a way in which to hone in on the specifics of place by targeting aspects that are unique and capture a destination's authenticity [14].

Heritage can form the basis for development, and can influence a destination's product offering. It can provide a new perspective on existing attractions, or a way in which to differentiate a destination [15]. It has been previously utilized to promote a positive image of a destination often including certain aspects of a destination's past while excluding others [16]. Heritage within TDI is thus, significantly market driven with little influence of its theoretical roots. Studies conducted in Japan's rural areas demonstrate that although all aspects of heritage increase local residents' sense of place, only selected fragments of heritage actually influence TDI [15]. Heritage may become a puppet to the creators of TDI, if utilized strategically by them [15]. In theory, all aspects of heritage have an influence on the organic image. However, typically only positive aspects of heritage are chosen in the construction of TDI.

\section{Cultural influence}

Culture differs from heritage in the sense that culture deals with the appreciation of people's way of life, their behaviours, attitudes and norms [17]. While as noted earlier, heritage contends primarily with history [10], culture is much more rooted in the present. Culture is a key dimension in portraying a destination's essence and sense of place. It provides a way for a place to enhance its reputation, and to make its place more real than commercialized. Culture provides a means for TDI to be genuine and agenda-free; it is a way in which image can become more authentic and match a destination's identity [18]. However, culture has been found to impact TDI through concealing poor aspects of a destination while highlighting positive components [19]. Research shows that culture portrays aspects of a destination that visitors favour and as such, causes visitors to either overlook or forget irritable or distasteful aspects of a destination [19].

Research has advocated that culture differences are crucial and effective elements of tourism promotion and should be implemented as part of image development [20]. Authors MacKay \& Fesenmaier [21], argue that each culture portrays a unique image and each individual perceives a unique image, creating a plethora of interpretations. As such, it is difficult to attribute which portions of TDI are influenced by culture. Authors Tasci \& Gartner [5], state that although culture has been analyzed to a lesser extent in research than other factors, it must be in some form influential on TDI. These two authors note that culture's influence on TDI needs to be more thoroughly examined by academia in order to conclusively state if a positive, negative or neutral relationship exists between the two. It would be beneficial to the understanding of not only culture's influence on TDI, but TDI itself, if primary research including quantitative data was obtained to substantiate theoretical assumptions.

\section{Influence of place identity}

Place identity, from a sociological perspective, focuses on the way in which the inhabitants of a set geographic area view themselves, the significance they attribute to their place, and the meaning it provides to them and their daily lives [22]. This definition can then be related to TDI by examining the way in which others perceive place identity.

The way in which a person's place identity influences TDI can be explored from different perspectives. One such perspective is personal image development. The way in which people view themselves is significantly correlated to the way in which they view their place [22]. Research has stated that every destination has a single-core identity that pre-dates any previous branding or image development [23]. This identity stems in part from the heritage and culture of a destination and the factors that differentiate it from other destinations [24]. The use and applicability of place identity in destination branding is a relatively new phenomenon to which DMOs (Destination Marketing Organizations) and other image developers have turned. In realization of the increasing competitiveness occurring within the tourism industry from other destinations, place identity has been a sought after way to differentiate [25]. A significantly unique place identity can alter TDI by subtly exerting its influence on image. For example, TDI can be influenced by the residents' perception of their own image. This occurs because locals will portray the image they already hold when they deliver services, interact and promote their destination. What this suggests is that the image that a destination portrays has much to do with the way in which the local inhabitants view their own image [18].

In realizing the influence of place identity on image development, numerous stakeholders have turned to heritage as a way in which to capture identity. Heritage has been viewed as a provider of collective memory, of a representation of the past and a stable symbol of place [26]. Thus, the way in which certain aspects of heritage are chosen in image depiction could change the collective memory of inhabitants and potentially alter the identity that locals derive from place. Thus, it is a culmination of factors such as heritage and history that display a location's sense of culture and way of life and are depicted through a destination's image [27].

\section{Influence of Stakeholder Involvement}

Numerous researchers have written about the involvement and participation of stakeholders from both marketing and social perspectives. It is important for communities to be involved with the formation and development of TDI. This is essential because TDI is reliant on the community portraying a consistent image with the destinations own overall image. When the inhabitants of a destination are involved in TDI, not only is the image much more rich and culturally sound, but also more authentic and genuine [28]. Including locals within image development allows the community to become stewards of their own TDI, 
and thus, by proxy defend the image against possible destruction and criticism [29]. With or without the consent of the developers of TDI (e.g., DMOs) various stakeholders have a discernable influence on a destination's image. Visitors, politicians, and businesses amongst others, all exert their own identities and agendas upon image, and thus, TDI reflects aspects of all stakeholders [30]. In order for TDI to be effectively formed and for the overall image to be consistent, many stakeholders must participate in image development. For instance, TDI may be destroyed or negatively projected if locals perceive that tourism has a negative impact on their community.

In addition, without the support of stakeholders, TDI can become highly fragmented and undecipherable. This causes a blurred image to be developed which not only reduces the effectiveness of TDI, but also causes friction amongst developers [4]. Respect among stakeholders is an important aspect of tourism destination development. If stakeholders have negative perceptions about each other and are unwilling to see one another's view of a destination then the image becomes highly dominated by one or two stakeholders [31]. The overall success of a destination's image requires a high degree of congruency amongst stakeholders, and without it, TDI gets negatively influenced and developed. Theoretically, this is a sound argument as it is easy to state that all stakeholders should be involved in image development. However, in reality aspects such as lack of education, power, and money separate those who actively develop the image versus those who cannot.

\section{Political \& Power influences}

Tourism is reliant on public goods; as such the politics revolving around tourism are different than those that affect other industries. Politics from a TDI perspective can thus be broadly defined as, the influence of various stakeholders, their competition with one another for power, the process of political affairs and the maneuvers used to exert influence [32]. One political aspect that influences TDI is the concept of funding and capital investment. Resources are scarce and political bodies such as local and federal governments have a significant impact in the allocation of funds. As such, creators and developers must partake in the interests of these political forces in order to continue receiving funds. However, the interests of these political powers often differ from those of various other stakeholders including the TDI developers themselves.

The type of tourism development projects chosen, the way in which they are marketed and the overall images that a destination provides are all influenced by political acts and forces. In addition, creators of destination image are consistently forced by political and economic factors to garner immediate financial and buzz worthy results [33]. Politicians want to see immediate results for their investments to garner more of the popular vote and secure their agendas, as opposed to investing in a project that is more beneficial for the long term. This can create constant new images that are not only fragmented, but heavily influenced by the agendas and biases associated with the particular politician/political entity in power at the time. TDI benefits from long-term investment, creation and development as is required when attempting to build a solidified brand [33].

It is difficult to analyze the influence of politics on image specifically as the concept is highly integrated with other aspects of tourism such as economics and culture. The politics of tourism tends to follow the status quo, or the destination's overall political scene. In this way, politics allows place image to be directly influenced by social and economic conditions, current demands and trends [34]. As aforementioned, stakeholder involvement is one of the numerous social influences affecting TDI, and since politics by nature reflects the influence of various stakeholders, image development becomes inherently politicized. One aspect of politics that has a direct influence on TDI is the system of society. A destination that embodies a functioning democratic system will have an easier time influencing image since it will be able to co-ordinate various stakeholders. In contrast, a destination with a conflicting political scene has more difficulty organizing and cocoordinating stakeholders, thus further fragmenting the image [32]. Tourism, and by proxy, TDI is seen by researchers as a way in which nations raise their global profile and garner accolades, to either increase their overall standing or maintain their lead. Countries unable to compete in other industries use destination image as a way in which to carve a place within the international political map [33].

Power is a concept within politics and tourism that is constantly being re-evaluated within society, with inequality being the determinant factor between the winners and the losers. Power can be defined as, the influence that one has over or within a specific situation or context [35]. Since politics deals with the interaction of people, such interactions allow for the struggles for power to develop in these relationships. As such, power involves aspects such as gender, age, socio-economic class and even sexuality. This power in influencing TDI, directly and proportionally reflects the power held by certain class differentials in everyday society. Thus, those who are disadvantaged, disenfranchised and lesser in power, have an equally minute influence on image and the way in which image is developed. TDI becomes a way in which global power relationships can be viewed. For example, the historical views of power, where developed nations controlled and ruled over the periphery, are evident within TDI, i.e. the north-south divide. According to Morgan and Pritchard [33], the countries previously considered among the periphery still project an image that is primitive and unchanged, offering a product that is inferior and cheap in comparison to neighbours to the north. These images distort the advances that these lesserdeveloped countries have made to date, and reinforce the notion that they are below and even lesser in power. This process becomes cyclical where nations with power use it to 
develop strong images, and those nations without, project poor images [33].

While some differences still exist, changes in the past 12 years have reduced the power differences among countries to a certain extent. For example, China, India and Brazil have risen dramatically in terms of GDP and power over the last decade and now exert a discernable influence in a variety of ways. Not only do these countries develop their own images and market themselves, but they also hold significant power on the global stage [36]. Thus, it can be suggested that this new power among the previously peripheral countries will cause changes in image development.

\section{Gender influences}

Gender plays an important role within destination image because it is part of the sociological framework that influences image creation. Thus, it can be defined as [37]: "a social construct, used to designate psychological, social and cultural aspects of maleness and femaleness." Gender influences the cultural and historical aspects of place and also plays a role in the distribution of power. It influences culture and history through its past and current implications. If a destination has portrayed women consistently as subservient, then the culture of such a destination would also be highly male dominated [38]. As such, women would occupy traditionally feminine occupations and be depicted in images with traditional, seductive or passive roles [39]. Gender also plays a key role in the distribution and use of power within society and therefore, within destination image development. In societies with stark differences between genders, where men are viewed as dominating figures, the power distribution tends to follow suit. As such, men hold the majority of power within these destinations and this image development is influenced almost solely by male views [38]. In addition, since men typically occupy a large portion of the executive decision making roles within these DMOs, and since they are unable to see the subtle gender cues within images, gender depiction often gets skewed. The images that are developed are fashioned in a patriarchal way with considerable influence given to male perspectives [39].

One aspect of gender that helps analyze the influence it has on destination image is the concept of gendered space. This construct can be defined as the innate characteristics a place, such as a destination, embodies that relate it to either masculinity or femininity [38]. Spaces can be viewed from different perspectives and offer different implications for both men and women. For example, some places offer more comfort to men to the exclusion of women, and vice versa [40]. In addition, Pritchard \& Morgan [39] suggest that destinations become gendered by the power relationships that exist within places; thus, popular media is heavily influenced by the male heterosexual viewpoint. This provides a crucial implication for TDI since image is developed using a place's characteristics. Thus, it could be advocated that the more masculine or feminine a place is, the more gendered the overall image will be.

Gender can be viewed as both a conscious and subconscious way of delivering intended messages carried out by the media and DMO's. These gender roles are often substantially lagging behind in comparison to current society. On a conscious level, gender is used in a strategic way to promote a certain type of feeling or emotion. For instance, when attempting to promote a product or destination with a feeling of relaxation or intimacy, marketers often use women within their images. In opposition, when attempting to portray a destination or product that is more active or strong, a man is portrayed [39]. The implication of this to destination image development is significant. In destinations such as the Caribbean and South East Asia, where women are considered unequal to men, the images portrayed often depict women as objects to be used or experienced. They are depicted in provocative and sensual positions, where their bodies are used to express sexual feelings. In contrast, societies where women hold power in comparable amounts to men such as North America, women are often depicted in more luxurious and sophisticated ways. Rather than women being used as objects of sexualized emotion, women are used to portray feelings of luxury and comfort [38].

All the above factors amalgamate together to create a highly gendered and sexualized landscape and thus, destination [41]. Since the destination itself becomes gendered, it is evident that gender has an influence on image development. For example, images derived by males can depict a male-centric view, and in essence alienate women and their needs. Women have been shown to inhibit feelings of irritation when viewing images of other women in subservient depictions [39]. This will negatively influence the women decision marker's choice of future destination selection [39]. Thus, the influence of gender can be said to diminish the quality of a destination image, if factors such as gender equality are not present.

\section{TOURISM DESTINATION IMAGE AS A SOCIAL SCIENCE CONSTRUCT - MODEL}

A model, Figure 1, has been developed to help illustrate the social science constructs that uniquely influence tourism destination image. It depicts the direction of the flow of influence of each factor as either being unidirectional or bidirectional. As such, some factors only influence TDI while others both influence and are influenced by TDI. Stakeholder involvement is one of the three factors of the model that is bidirectional. This involvement has been continuously supported in academic literature as being of crucial importance to the success of a destination [42]. By allowing numerous stakeholders to influence TDI development, the overall image becomes more rich, authentic, and accurately representative [28]. As such, 


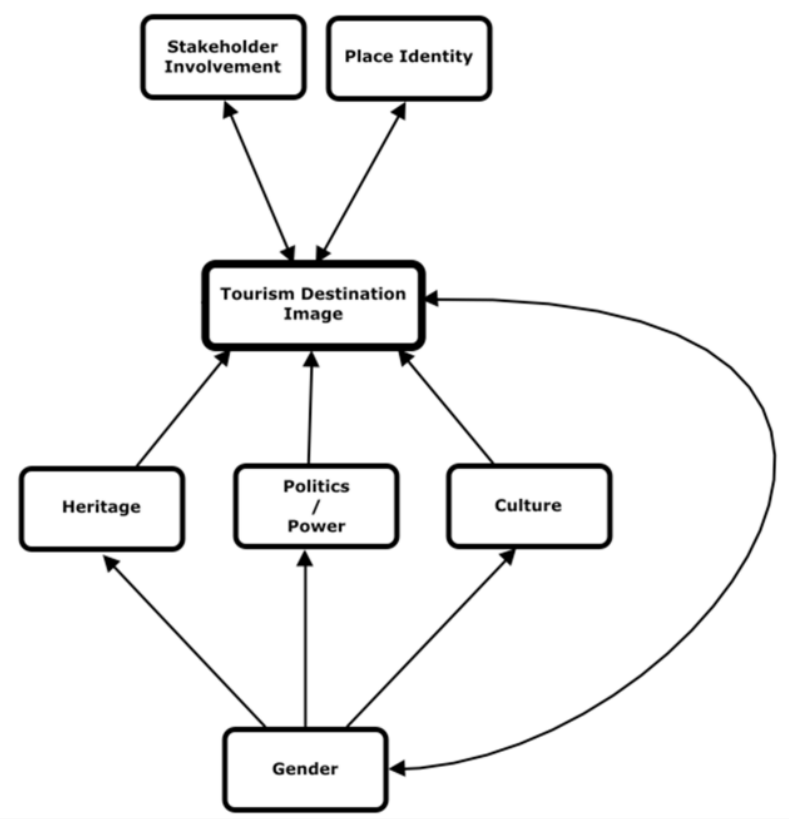

Figure 1: Tourism Destination Image as a Social Science Construct

stakeholders can have considerable influence on image if given the opportunity. In addition, image also influences stakeholder involvement. If the image is representative and inclusive, then stakeholders will be not only more willing to participate in the development process but also become excellent stewards of the image [29].

Place identity is another social science construct that both influences and is influenced by destination image. The way in which place identity influences destination image is through personal image development of inhabitants [22], and the pre-existing image of the place [23]. Since creators of TDI are often local inhabitants, their personal image of place influences the image they develop. In addition, since all places have a unique pre-existing image prior to any development, this identity subtly influences TDI. In comparison, TDI influences place identity by depicting only certain aspects of a place's heritage and culture [16]. This depiction can cause change in the collective memory of inhabitants and thus, can change the identity that locals derive from place.

Finally, gender is a social science construct that not only influences destination image but is also influenced by TDI. It also has an influence on politics, power, heritage and culture. Gender influences culture and heritage by creating distinct societies where the differences between genders are portrayed. This inequality influences the power distribution within the destination, which then factors into the image development process [38]. Gender influences TDI because the images developed and utilized by a destination are influenced by gendered landscapes. In addition, the level of equality among men and women in a place affects the types of images chosen [39]. Finally, destination image also influences gender in that the current image portrayed by a destination will impact each gender's purchase selection differently.

Heritage is a social science construct that can be said to have a unidirectional influence on destination image. Heritage influences people's perceptions and evaluations and thus, one's cognitive and affective image of place [12]. It influences TDI as a means of differentiation [15] to promote a positive image of a destination. The heritage of a place is utilized and selected strategically by TDI creators in order to create this positive image.

Culture differs from heritage in the sense that culture deals with the appreciation of people's way of life, their behaviors, attitudes and norms [17]. As such, culture also directly influences destination image since it is used to enhance the reputation of a place, and make the image seem more genuine. Culture has been shown to project aspects of a destination that visitor's favor, which is why it is used as an influence in destination image development.

Another social science construct that influences destination image is politics and by proxy, power. Politics influences TDI since the former is the process of political affairs that are undertaken to garner and exert power and influence [33]. TDI requires funding and investment, which is primarily provided by governments. As such, this funding allows governments to have great influence on the way image is created. Power influences TDI because those who hold power are able to mould and affect the creation of TDI [33]. Those with power through class differentials, gender, age and socio-economic status use their preferential place to exert their views on image development.

\section{CONCLUSION}

Tourism destination image is a concept that accounts for the sum of beliefs, ideas and impressions that a person has of a destination [1]. This complex concept has been analyzed to gauge the influences that certain social science constructs have upon it. Social science is the study of human society and of individual relationships in and to society [9]; as such it has a significant influence on destination image, which deals directly with society and place. Constructs of social science, from culture to gender have a discernable and different influence on destination image. Some constructs strengthen the overall image, while others have the potential to create a fragmented and artificial image. Although academic research has attempted to understand these influences, ambiguity still exists. This paper has attempted to amalgamate current research within these disciplines in order to model their relationships as a step toward understanding the influence of these constructs on TDI.

\section{REFERENCES}

1. Crompton, J. (1979). An assessment of the image of Mexico as a vacation destination and the influence of 
geographical location upon that image. Journal of Travel Research, 17(1), pgs. 18-23.

2. Byon, K. \& Zhang, J. (2010). Development of a scale measuring destination image. Marketing Intelligence \& Planning, 28(4), pgs. 508-532.

3. Jenkins, O. (1999). Understanding and measuring tourist destination images. International Journal of Tourism Research, 1(1), pgs. 1-15.

4. Ooi, C. (2004). Poetics and politics of destination branding: Denmark. Scandinavian Journal of Hospitality and Tourism, 4(2), pgs. 107-128.

5. Tasci, A. \& Gartner, W. (2007). Destination image and its functional relationships. Journal of Travel Research, 45(4), pgs. 413-425.

6. Phillips, W. \& Jang, S. (2010). Destination image difference between visitors and non-visitors: A case of New York City. International Journal of Tourism Research, 12(5), pgs. 642-645.

7. Beerli, A. \& Martin, J. (2004). Factors influencing destination image. Annals of Tourism Research, 31(3), pgs. 657-681.

8. "Social Science." (2010). In Merriam-Webster Online Dictionary. Retrieved December 12, 2010, from http://www.merriam-

webster.com/dictionary/social+science?

9. Okech, R. (2010). Socio-cultural impacts of tourism on world heritage sites: Communities perspective of Lamu (Kenya) and Zanzibar Islands. Asia Pacific Journal of Tourism Research, 15(3), pgs. 339-351.

10. Yankholems, A. \& Akyeampong, O. (2010). Tourist' perceptions of heritage tourism development in DanishOsu Ghana. International Journal of Tourism Research, 12(5), pgs. 603-616.

11. Gelbman, A. \& Ron, A. (2009). Heritage and cultural tourism: The present and future of the past. Tourism Geographies, 11(1), pgs. 127-129.

12. Royo-Vela, M. (2009). Rural-cultural excursion conceptualization: A local tourism marketing management model based on tourist destination image measurement. Tourism Management, 30(3), pgs. 419428.

13. Gonzalez, M. (2008). Intangible heritage tourism and identity. Tourism Management, 29(4), pgs. 807-810.

14. Jewell, B. \& Crotts, J. (2002). Adding psychological value to heritage tourism experiences. Journal of Travel \& Tourism Marketing, 11(4), pgs. 13-16.

15. McMorran, C. (2008) Understanding the 'heritage' in heritage tourism: Ideological tool or economic tool for a Japanese hot springs resort? Tourism Geographies, 10(3), pgs. 334-354.

16. Hughes, H. \& Allen, D. (2005). Cultural tourism in central and eastern Europe: The views of induced image formation agents. Tourism Management, 26(2), pgs. 173183.

17. Barbieri, C. \& Mahoney, E. (2010). Cultural tourism behaviour and preferences among the live-performing arts audience: an application of the univorous omnivorous

framework. International Journal of Tourism Research, 12(5), pgs. 481-496.

18. Anholt, S. (2007). Competitive Identity: The New Brand Management for Nations, Cities and Regions. Palgrave Macmillan: Wales (UK).

19. Ong, B. \& Horbunluekit, (1997). The impact of a Thai cultural show on Thailand's destination image. American Business Review, 15(2), pgs. 97-103.

20. Reisinger, Y. \& Turner, L. (2002). Cultural differences between Asian tourist markets and Australian hosts, part 1. Journal of Travel Research, 40(3), pgs. 295-315.

21. MacKay, K. \& Fesenmaier, D. (2000). An exploration of cross-cultural destination image assessment. Journal of Travel Research, 38(4), pgs. 417-423.

22. Droseltis, O. \& Vignoles, V. (2010). Towards an integrative model of place identification: Dimensionality and predictors of intrapersonal-level place preferences. Journal of Environmental Psychology, 30, pgs. 23-34.

23. Mayes, R. (2008). A place in the sun: The politics of place, identity, and branding. Place Branding and Public Diplomacy, 4(2), pgs. 124-135.

24. Hall, M. (2008). Servicescapes, designscapes, branding, and the creation of place-identity: South of Litchfield, Christchurch. Journal of Travel \& Tourism Marketing, 25(3), pgs. 233-250.

25. Ekinci, Y. \& Hosany, S. (2006). Destination personality: An application of brand personality to tourism destinations. Journal of Travel Research, 45(2), pgs. 127139.

26. McLean, F. \& Cooke, S. (2003). Constructing the identity of a nation: The tourist gaze at the museum of Scotland. Tourism Culture \& Communication, 4(3), pgs.153-162.

27. Pritchard, A. \& Morgan, N. (2001). Culture, identity and tourism representation: Marketing Cymru or Wales? Tourism Management, 22(2), pgs. 167-179.

28. Park, O., Cai, L., \& Lehto, X. (2009). Collaborative destination branding. Bridging tourism theory and practice. Emerald Publishing Limited, Bingley, UK.

29. Baker, B. (2009). Consultation builds stronger brands. Tourism branding: communities in action. Bridging Tourism Theory and Practice, 1. Emerald Group Publishing Limited.

30. Saraniemi, S. (2010). Destination brand identity development and value system. Tourism Review, 65(2), pgs. 52-60.

31. Cooper, C., Scott, N. \& Baggio, R. (2009). Network position and perceptions of destination stakeholder importance. Anatolia: An International Journal of Tourism and Hospitality Research, 20(1), pgs. 33-45.

32. Ryan, J. \& Silvanto, S. (2010). World heritage sites: The purposes of politics of destination branding. Journal of Travel and Tourism Marketing, 27(5), pgs. 533-545. 
33. Pritchard, A. \& Morgan, N. (1998). Tourism promotion and power: Creating images, creating identities. John Wiley \& Sons, New York: NY.

34. Shanks, C. (2009). The global compact: The conservative politics of international tourism. Futures, 41, pgs. 360366.

35. "Power." (2010). In Merriam-Webster Online Dictionary. Retrieved December 12, 2010, from http://www.merriam-webster.com/dictionary/power

36. Georgieva, K. (2006). BRIC countries in comparative perspective. World Bank.

37. Wilkinson, P. \& Pratiwi, W. (1995). Gender and tourism in an Indonesian village. Annals of Tourism Research, 22(2), pgs. 283-299.
38. Pritchard, A. \& Morgan, N. (2000). Privileging the male gaze: Gendered tourism landscapes. Annals of Tourism Research, 27(4), pgs. 884-905.

39. Sirakaya, E. \& Sonmez, S. (2000). Gender images in state tourism brochures: an overlooked area in socially responsible tourism marketing. Journal of Travel Research, 38(4), pgs. 353-362.

40. Fortuijn, J., Horn, A., \& Ostendorf, W. (2004). 'Gendered spaces' in urban and rural contexts: An introduction. Geojournal, 61(3), pgs. 215-217.

41. Pan, S. \& Ryan, C. (2007). Gender, framing \& travelogues. Journal of Travel Research, 45(4), pgs. 464474.

42. Aas, C., Ladkin, A., \& Fletcher, J. (2005). Stakeholder collaboration and heritage management. Annals of Tourism Research, 32(1), pgs. 28-48. 